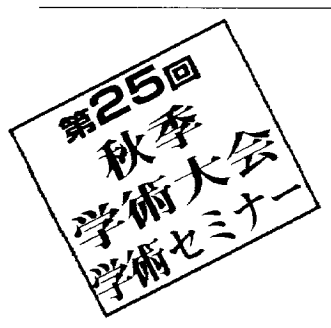

会期：平成 9 年10月31日

会場：奈良商工会議所会館

\title{
SPECT两像の周波数解析
}

大西英雄

滋賀医科大学医学部附属病院放射線部

\section{Frequency Analysis of SPECT Images}

Hideo Ohnishi

Department of Radiology. Shiga University of Medical Science

\section{1.はじめに}

核医学における放射性医薬品の開発やSPECT装置の 進歩には目を見張るものがある。特に近年，SPECT処 理装置の高速化に伴い精度の高いSPECT画像がより要 求さ机ている，SPECT画像自体に大きく影響する因子 として，1)フィルタ処理 '，2) 吸収・散乱処理 (TCT 法'やTEW法3'など)，3)部分容積効果4)よ゙が考えら れる。しかし，SPECT画像再構成の根幹を成している フィルタ処理は, 周波数空間で論じているにもかかわ らず，実際は再構成されたSPECT画像を主観的に判断 して評価しているのが現状である。そこで，基本に立 ち戻って実空間の画像を周波数空間に誘い「画像と周 波数」との関係を一次元的な考之力から実際の実空間 の二次元画像に置き換え二次元パワースペクトル分布 から周波数空間での特徵を考察する。またその応用編 として, テクスチャ解析の周波数解析法を利用して SPECT画像加持つ周波数分布を定量的に解析し, 実際 のSPECT画像の最適つィ ルタの評洒に応用する。

\section{2. 画像と周波数}

一般にある入力波形(入 力信号)は，一次元フーリ 工変換を行うことにより 周波数領域の信号に変換 することができる。すな わち, 入力信号を特定の 周期関数 $(\sin , \cos$ 等) で表 現し, 繰り返し数 (周 期)，強度(強さ)およびず れ(位相)等で表現する。 そこで, 周期および強度 入力波形がどのような周 波数成分から構成されて
いるかを調べることは，時間波形などの一次元信号処 理・解析"にに扮いて重要な手段となっている。二次元 信号である画像情報に対しても，濃淡情報の空間的な 広がりに着目して空間周波数という概念を導入し，入 力画像がどのような空間周波数成分から構成されてい るかを調べたり，空間周波数領域で種々の処理を施し たりすることが可能となる，空間周波数は，単位長さ 当たりの正弦波状 ( $\sin , \cos$ なと）の濃淡変化の繰り返 し回数を示すものである (Fig.1). この考え万を二次元 に応用すると, 縦軸, 横軸におのおの $\mathrm{x}$ 軸方向, $\mathrm{y}$ 軸 方向に対応した空間周波数 $u, v$ をとた二次元平面 (空間周波数領域)を用いて表現される5).Fig.2は，空 間的な濃淡の変化の様子と, 対応する空間周波数を示 したものである.（a）（b）は $\mathrm{x}$ 軸方向だけに二次元正 弦波状の濃淡变化がある場合，(c)は斜め方向に二次 元正弦波の濃淡変化が生じる場合であり，x軸および $\mathrm{y}$ 軸に沿っての断面により, $\mathrm{x}$ 軸および $\mathrm{y}$ 軸方向の濃

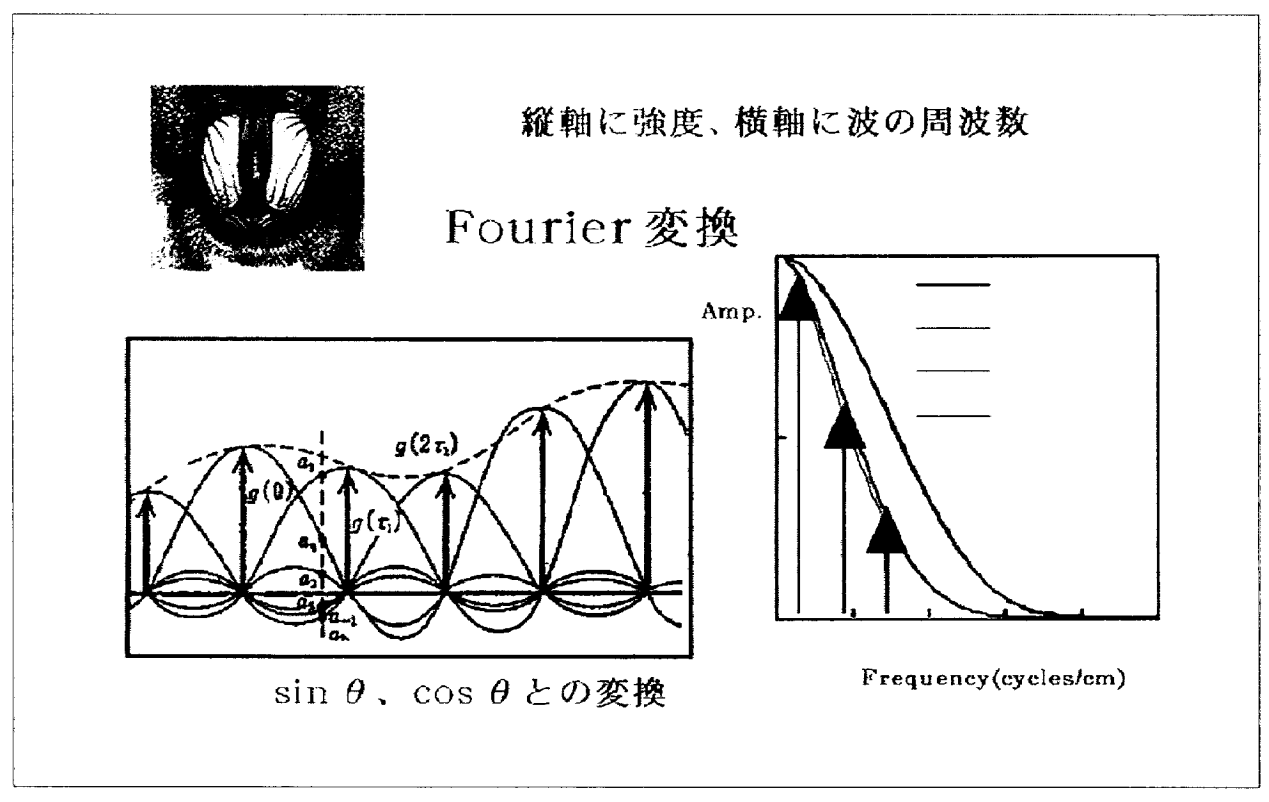

Fig. 1 実空間から周波数空間への変換 (一次元的). 
(a)

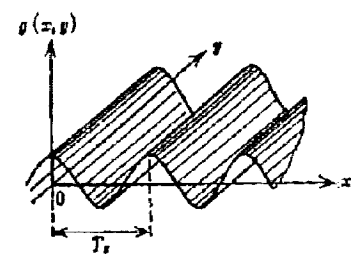

(b)
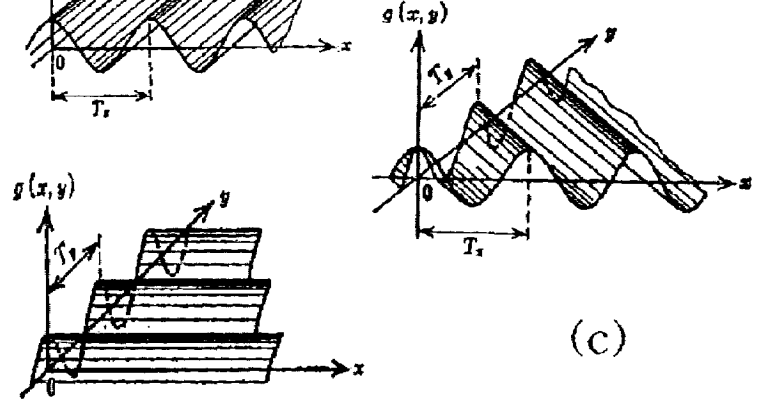

(c)

Fig. 2 実空間加周波数空間への变換 (二次元的).

直流成分（入力函像の濃度値の総和）

$\Delta \mathrm{y}$

低周波成分に対时

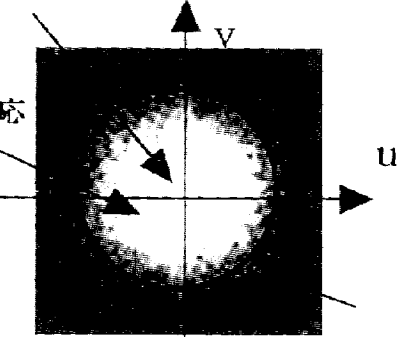

$\psi(u, v)=\lim _{X \rightarrow \infty} \frac{1}{X Y} \mathrm{H}\left[\mid F_{Y Y}(u, v)^{2}\right]$

高周波成分に対成

Fig. 3 二次元パワースペクトル(log-power)分布の特性.

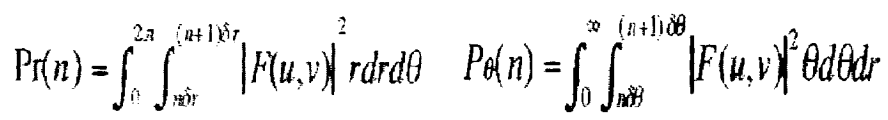

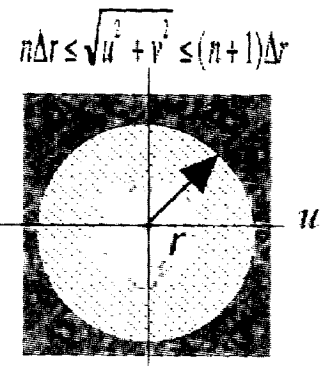
$\left.n+\theta \leq \tan \left(u^{\prime}\right) \leq(n+1)\right](\theta)$

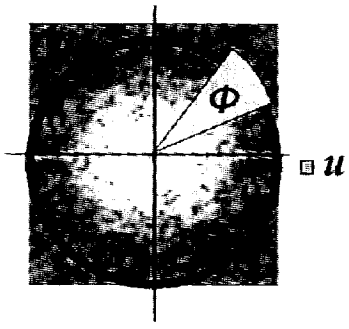

Fig. 4 動径方向強度分布関数 $\operatorname{Pr}(n)$ と角度方向強度分布関数 $P_{\theta}(n)$ の 関係式.

淡変化の繰り返し回数，すなわち空間周波数(周波数 の頻度)を求めることができる。こ机から求めた周波 数分布(一般的にフーリ工変換をすると実数部と虚数
部ができる)からパワースペクトルを求める (周波数成分の絶対值の 2 乗)。この二次元パ ワースペクトルから二次元画像が持っている 周波数特性を求める. 二次元パワースペクト ルは，中心に画像の直流成分をとり，内側か ら外側にむかって低周波一高周波領域に対応 している Fig.3)。この二次元パワースペクト ル分布 (log-power)の特徴としては，(1)ゼロ 周波数は入力画像のピクセル值の総和であ る、(2) 絴軸(強度)はゼ口周波数のダイナミッ クレンジに合わせて強度分布の対数を取って 表示する，(3)横軸は(周波数軸)は標本化定理 に徥う（Nyquist周波数 $=1 / 2 \mathrm{~d}=0.5$ cycle/pixel），

(4) 分布自体は原点対称である. (5) 方向依存 性がある，などのような性質を利用して周波 数空間から画像の特徵抽出を行う。特に, 核医学画像 のSPECT画像は周波数空間での表現がフィル夕関係に 上く用いられるため,フィルタについて解析を行う。

\section{3. 二次元パワースペクトルからの特䁌抽出およびそ の評価法}

二次元画像 $f(x, y)$ の二次元フ-リ工変換 $F(u, v)$ は 次式で表される。

$$
F(u, v)=\iint_{-\infty}^{\infty} f(x, y) e^{-j(u r+v y)} d x d y
$$

ここで， U、ははそれぞれ $\mathrm{u}$ 方向，v方向の空間周波数 である。また，周波数成分の絶対值の 2 乗 $|F(u, r)|^{2}$ は，二次元パワースペクトルとして表現され る。この二次元パワースペクトルから下記に 示寸指標を使用して画像評価を行う。

\section{3-1 動径方向強度分布関数 $(\operatorname{Pr}(n))^{6}$ )}

Fig.4に示すようにパワースペクトルの周波 数空間 $(u, v)$ に扔いて同心円上の周波数带域 を考えると半径 $r$ は周波数に相当する。半径 $r$ における幅 $\delta r$ のリング内の z 軸，すなわ ちパワースペクトルの強度の総計を $\operatorname{Pr}(n)$ と 扮けば式(2)は成り立つ。

$$
\operatorname{Pr}(n)=\int_{0}^{2 \pi} \int_{n \dot{x}}^{(n+1) \delta x}|F(u, v)|^{2} r d r d \theta
$$

ただし，半徍 $r$ は $n \delta \leq \sqrt{u^{2}+r^{2}} \leq(n+1) \delta \cdot の$ 範囲である。したがって, $\operatorname{Pr}(n)$ はすべての 方向について原点からの距離 $r$ に関する $F(u$, r)の棇和となり, 対象とする画像 $f(x, y)$ のピクセル值 の変化が大雑把で少ないほど， $F(u, v)$ の原点近くの值 が大きくなる. $f(x, y)$ のピクセル値の変化が細かく微 
妙になるに従い, $F(u, v)$ 上 の大きな值の部分は原点か ら遠ざかる。このPr(n)か ら二次元画像の周波数分布 を一次元的に評価寸る.

\section{3-2 動径角度強度分布関} 数 $\left(P_{\theta}(n)\right)^{6)}$

Fig.4に示すようにパワ ースペクトルの周波数空間 $(u, v)$ に扔いて同心円を考 之, $\mathrm{u}$ 軸加角度 $\theta$ を変化 させてFig.4に示す斜線で 囲を扇型の強度の総計を動 径俑度強度分布関数 $P_{\theta}(n)$ と定義する。

$$
P_{\theta}(n)=\int_{0}^{\infty} \int_{n \delta \theta}^{(n+1) \delta \theta}|F(u, v)|^{2} \theta d \theta d r
$$

ただし， $\theta$ は $n \delta \theta \leq \tan -1(v / u) \leq(n+1) \delta \theta$ 範囲で 变化する。解析方向に関して $f(x, y)$ と $F(u, v)$ とは扔互 いに直交する関係にある。すなわち $f(x, y)$ が $\mathrm{x}$ 方向に ついて物体のパターンを持つと，そのフーリ工変換の 結果は90度回転した v 方向に現れる。P $P_{\theta}(n)$ は u軸に $\delta \theta$ 角度のスペクトルで二次元画像が含んでいる角度 情報を抽出する。

\section{4. 核医学画像評価への応用}

4-1 核医学画像およびコリメータシステムの周波数 分析 ${ }^{7}$

Fig.5にSPECT画像, planar 画像, SPECT画像 (ramp) のそれぞれの画像のパワー スペクトルの動径強度分布 関数P $r(n)$ を示す. 脳つア ントム存使用し白質と灰白 質との放射能強度比が 1 ： 4 になるように調整し， 64×64マトリクスで収集し た. SPECT画像は前処理〉 イルタにButterworthフィル 夕 $(\mathrm{Fc}=0.25 \mathrm{cycle} / \mathrm{pixel})$ を用 い, 再構成フィルタにramp 関数で画像再構成をした。 SPECT画像 (ramp) は前処 理は行わず再構成フィルタ (ramp関数)のみで画像再構

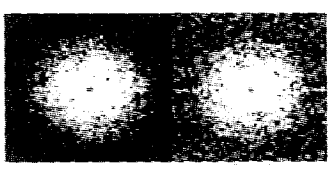

成したものである。Fig.5のPr $(n)$ の比較では, planar 画像がSPECT画像よりも信号領域の周波数帯域のダイ ナミックレンジが広い，また周波数成分 $(0.3 \sim 0.5$ cycle/pixel)の範囲でのSPECT画像のPr $(n)$ 分布の低下 は, Butterworthフィルタ $(F c=0.25$ cycle/pixel) の影響 で高周波成分が抑えられているのが表現できている. SPECT画像抢よびSPECT画像 (ramp) とのPr $(n)$ の差 (0.25 0.5cycle/pixelの範囲) は，画像再構成時での高周 波ノイズを明瞭に示している. Fig.6でのP $P_{\theta}(n)$ では，分 布パターンは同じ対象物(脳ファントム)なので顕著な 変化は見られないが, コリメー夕感度(HR-GP-HS)が 低くなるにつれてP $(n)$ の值は大きくなっている。これ
動径方向强度分布関数

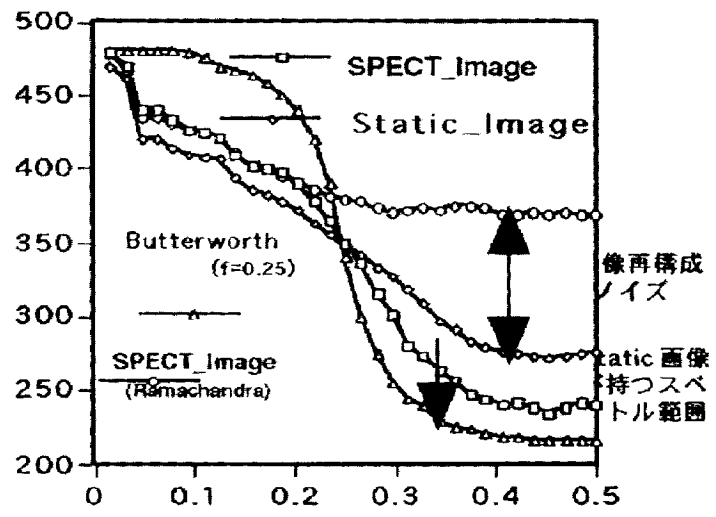

Fig. 5 実際の画像スペクトル分布での対比(動径方向強度分布関数 $\operatorname{Pr}(\mathrm{n}))$.

LEGP Static HR

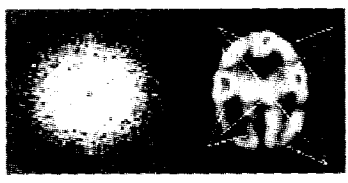

LEHR

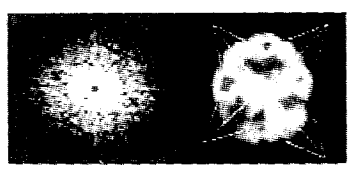

LEHS
角度方向強度分布関数

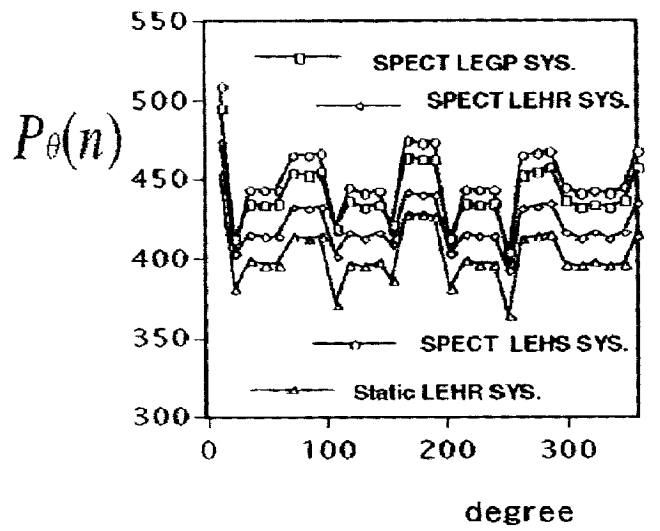

Fig. 6 実際の画像スペクトル分布での対比(角度方向強度分布関数 $\mathrm{P}_{\theta}(\mathrm{n})$ )). 
は角度方向の分解能を表現している。使朋するコリメ 一夕の種類でのP $r(n)$ をFig.7に示す．やはりplanar画像 の周波数帯域はSPECT画像のそ北に比較して大きく,

LEHS $=0.174$, LEGP $=0.270, \quad$ LEHR $=0.382$ (cycle/pixel) となり,コリメータの種類での分解能の差が明確に娭 出できている。Fig.7によりSPECT画像とSPECT画像 (ramp)のPr. $(n)$ 上での低周波数の重なり(0.005 0.15 cycle/pixel)の傾きはLEHS $<$ LEGP $<$ LEHRの順で広 くなり，LEHRコリメータのスペクトル分布の周波数 带域の広さを示している。また，ノイズ領域の值が LEHS $>$ LEGP $>$ LEHRの順で小さくなり, データ収集時 の使用コリメータのノイズ特性も顕著に表現できる。
4-2 Butterworthフィルタにおける最適遮断周波数の 検討

\section{4-2-1 心筋SPECT画像における最適遮断周波数 ${ }^{8)}$}

心筋ファントム $(\mathrm{RH}-2$ 型，株式会社京都科学製)を 使用し， ${ }^{201} \mathrm{~T} 1 お よ ひ ゙ 99 \mathrm{~m}$ Tcでの心筋SPECT画像におけ るButterworthフィルタの最適遮断周波数を検討した。 収集条件は，64×64マトリクス，180度収集，1step/ 6 度/30秒 60view. 収集データに対して, Butterworth フィルタ (order：8)を用いて, 0.1 0.3cycle/pixel $(0.187 \sim 0.562 \mathrm{cycle} / \mathrm{cm})$ までの範囲で遮断周波数 $(F c)$ を $0.025 \mathrm{cycle} / \mathrm{pixel}$ 間隔ごとに変化させて処理画像とす る。基準画像の收集条件は，64×64マトリクス，180 度収集, 1 step/ 6 度/150秒 60viewとし，前処理フィル タなしで再構成フィルタを ramp関数のみで再構成を行 った。それぞれのSPECT画 像の周波数解析を動径強 度分布関数Pr $(n))$ 妾用いて 評洒し，基準画像のPr $(n))$ の最小 2 乗鿁差8 をとり， その最小值の遮断周波数を 最適遮断周波数とした。

Fig.8に ${ }^{201} \mathrm{Tl}$ と $^{99 \mathrm{~m}} \mathrm{Tcによ}$ るSPECT画像のPr $(n)$ を示 す。 ${ }^{201} \mathrm{Tl} の$ 場合, 遮断周波 数を変化させても融 $\mathrm{Tc}$ 比較して変化を示さなか った。基準画像と処理画 像との最小 2 乗䛊差からの 最適遮断周波数は, LEGP で0.245cycle/pixel, LEHR で0.25cycle/pixelとあまり 変化はなかった。しかし， Fig.9に示すように299mTcに よるSPECT画像のPr $(n)$ で は, Butterworthフィルタ OF $\mathrm{C}$ を変化させると画像 の周波数スペクトルも大 きく変化L，SPECT画像 と周波数分布の違いが理 解できる。また，Pr $(n)$ か らも, $0.1 \sim 0.3$ cycle/pixel の範囲においてLEHRのス ペクトル強度がLEGPのそ れと比較して大きく，ま たダイナミックレンジの 広いシステムであること

Fig. $8{ }^{201}$ T1心筋ファントムでの二次元パワースペクトルおよび動径方向強度分布関数 $\operatorname{Pr}(n)$. 
が分かる。Fcを変化させ た場合にLEHRの変化が大 きい。このことは，LEGP に比べLEHRがフィルタ処 理に敏感に変化すること を物語っている，基準画 像と処理画像との最小2 乗 誤差からの最適遮断周波 数は, LEGPで0.25cycle/ pixel, LEHRで0.27cycle/ pixelと大きく変化した 同じ標的臓器(ファント ム)でもエネルギーが変化 すれば周波数分布も変わ り，また分解能の異なる システムでも大きく変化 することが分かる。核種 およびコリメータによっ てフィルタの遮断周波数

を変化させる必要性があることが理解できる。

4-2-2 脳血流SPECT画像における最適遮断周波数9)

Brainファントム(株式会社京都科学製)を使用し, 99!Tcでの脳血流SPECT画像におうるButterworthフィ ルタの最適遮断周波数を検討した。 Brainファントム には，臨床データのSPECT画像の平均值から求めた白 質と灰白質の放射能強度の比が $1: 4$ になるように ${ }^{99 \mathrm{~m}} \mathrm{Tc}$ 溶液を調整した。収集条件は，64×64マトリク ス，360度収集，1step/6度/30秒 64view。吸収補正は Chang法を用い吸収係数 $\left(\mu=0.1 \mathrm{~cm}^{-1}\right)$ を用いて行っ た。収集デー夕に対して，Butterworthフィル夕 (order：8) を用いて，0.1〜0.3cycle/pixel (0.292 $0.874 \mathrm{cycle} / \mathrm{cm})$ までの範囲で遮断周波数

$(F c)$ を $0.025 \mathrm{cycle} / \mathrm{pixe1}$ 間隔ごとに変化さ せて処理画像とする，基準画像の収集条 件は，64×64マトリクス，360度収集， 1 step/ 6 度/200秒 64viewとし, 前処理フィ ルタなしで再構成フィルタをramp関数のみ で再構成を行った。それぞれのSPECT画 像の周波数解析を動径強度分布関数 $\operatorname{Pr}(n)$ を用いて評価し，基準画像のP $r(n)$ の最小 2 乗誤差》をとり，その最小值の遮断周波 数を最適遮断周波数とした。

Fig.10にLEGPおよびLEHRコリメータ 使用時のSPECT画像でのPr $(n)$ を示す。 使用するコリメータによる差は大きく， 特に0.23〜1.242cycles $/ \mathrm{cm}$ の周波数帯域で はLEHRコリメータを用いた信号強度が LEGPに比較して広い。また，基準画像
と遮断周波数の関係ではLEGPコリメータは $0.583 \mathrm{cycle} /$ $\mathrm{cm}$, LEHRコリメータでは0.729cycle/cmの遮断周波数 が基準画像のP $\operatorname{Pr}(n)$ に近い分布曲線となっている。 な お, 基準画像と処理画像と $\operatorname{PPr}(n)$ 分布での最小 2 乘法 による解析9では, LEGPコリメータで0.583cycle/cm, LEHRコリメータで $0.656 \mathrm{cycle} / \mathrm{cm}$ が最適遮断周波数と なった。これは, 実空間での評価法(NMSE法)帛とほほ 一致している。

\section{4-3 標的臟器の違いによる画像周波数特性の検討}

検査を行う標的藏器の違いにより, 得られたSPECT 画像の周波数带域をFig.11に示す。これは, あくまで

1998 年 10 月

$99 \mathrm{mTC}$
LEGP

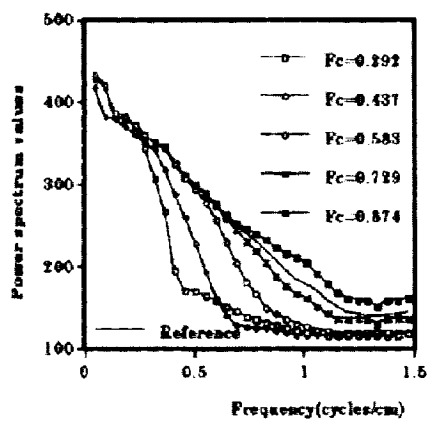

(A)
LEHR

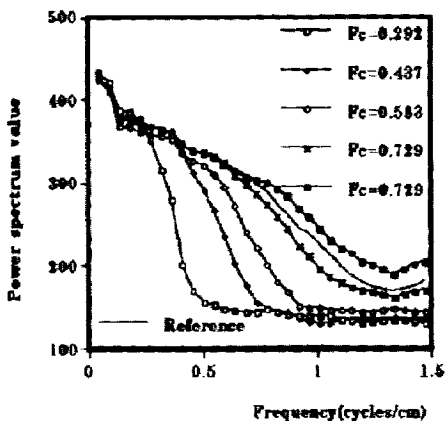

(B)
Fig. 10 Brainファントムにおける動径方向強度分布関数 $\operatorname{Pr}(n)$. 
ファントム上でのスペクトルであるが，比較的簡単な 形状をしている心筋SPECT画像では，低周波成分が高 周波成分に比べて多く, 複雑な臓器である脳SPECT画 像は，かなり高周波成分までスペクトル分布が広がっ ているのが理解できる，また，標的臓器での検查の装 置間のpixelサイズが異なるため，同一の尺度である cycle/cmを使って表現してみる。心筇ファントム (pixel-size $: 0.533 \mathrm{~cm} / \mathrm{pixel})$, 脳ファントム (pixelsize : $0.343 \mathrm{~cm} / \mathrm{pixel})$. 細がpixel-sizeで収集された 脳ファントムと心筇ファントムの周波数分布に大きな 差が生じている。これもまた，標的臟器により遮断周 波数を変化させる必要性があることを示唆するもので ある。

\section{5. まとめ}

SPECT画像を使った定性的な時代は終わり， SPECT画像の定量性を重視した時代となりつつある現 在において, 画像再構成は画像の根幹を占める。 SPECT画像再構成についてはいくつかの問題がある が，フィルタを考える場合においては，周波数空間で フィルタを論じる必要性が生じてくる．周波数領域で フィルタの選択を十分考慮して決定しなければならな い. 収集システム系が変化し，投与する核種が異なれ ば信号スペクトル分布は大きく変化する．感度が高 く，エネルギーが低くなるにつれて画像に含まれる信 号成分と雑音成分の比率が小さくなりButterworthフィ ルタの遮断周波数 $\left(F_{C}\right)$ は低周波領域に移行する。ま た，標的蔵器の違いによりその臓器に含まれる周波数 帯域を十分把握して，投与量等に関して も併せて10フイルタ效果を確認しなけれ ばならない。今後，散乱・吸収抢よび部 分容積効果の問題点がクリアすれば, SPECT画像の定量化には一段と拍車がか かるであろう。PETにない簡便さおよび 普及度からして大きくSPECT画像が前進 することと思う。

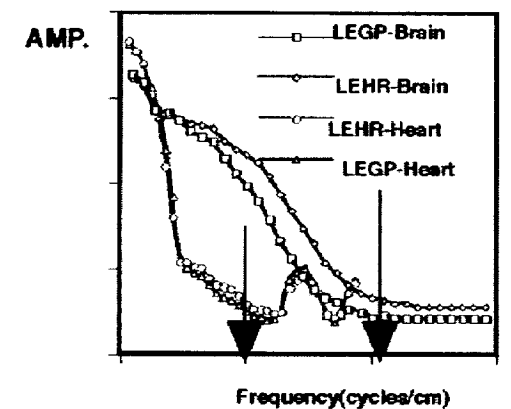

Frequency(creles/cri)

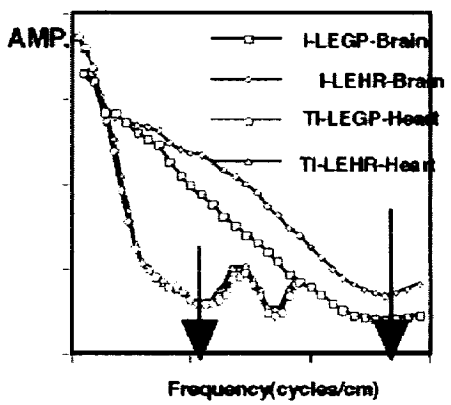

Fig. 11 標的臟器での画像周波数特性（心筋ファントム, Brainファント 厶).

\section{参考文献}

1) Madsen MT and Park CH: Enhancement of SPECT images by Fourier filtering the projection images set. J. Nucl. Med., 26, 395-402, (1985).

2) Ichihara T, Motomura N, Ogawa K, et al.: Evaluation of SPECT quantification of simultaneous emission and transmission imaging of the brain using a multidetector SPECT system with TEW scatter compensation method and fan-beam collimation. Eur. J. Nucl. Med., 23, 1292-1299, (1996).

3) Ichihara T, Ogawa K, Motomura N, et al.: Compton-scatter compensation using the triple energy window method for single and dual isotope SPECT. J. Nucl. Med., 34, 2216-2221, (1993).

4) 森下 嚴, 小畑秀文: 信号処理. 計測自動制御学会, (1981).

5)田中 弘：画像処理応用技術. 工業調查会, (1989).

6) Paratt WK: Digital Image Processing (second edition). pp.685686, John Wiley \& Sons, Inc., New York, (1991).
7) 大西英雄, 高橋雅文, 松尾 悟, 他:テクスチャー解析法 を用いたSPECT画像評価. 日放技学誌，51(6)，710-716， (1995).

8) 大西英雄, 松尾 悟, 牛尾哲敏, 他: $99 \mathrm{~m}-\mathrm{Tc}$ 心筋血流 SPECT画像に执けるButterworth filterの評洒. 日放技学 誌, 52(3), 346-350, (1996).

9) 大西英雄, 木田哲夫, 野間和夫, 他：脳血流SPECT画像に 扔けるButterworth filterの最適遮断周波数の検討一実空間 および周波数空間での評価一。日放技学誌，54(6)，764770, (1998).

10) Ohnishi H, Ota T, Takada M, et al.: Two optimal prefilter cutoff frequencies needed for SPECT images of myocardial perfusion in a one-day protocol. J. Nucl. Med. Technol., 25 (4), 256260. (1997). 